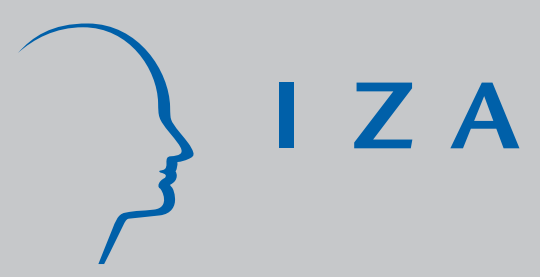

IZA DP No. 3598

On Amenities, Natural Advantage and Agglomeration

Douglas] . Krupka

J uly 2008 


\title{
On Amenities, Natural Advantage and Agglomeration
}

\author{
Douglas J. Krupka
}

IZA

\author{
Discussion Paper No. 3598 \\ July 2008
}

\author{
IZA \\ P.O. Box 7240 \\ 53072 Bonn \\ Germany \\ Phone: +49-228-3894-0 \\ Fax: +49-228-3894-180 \\ E-mail: iza@iza.org
}

\begin{abstract}
Any opinions expressed here are those of the author(s) and not those of IZA. Research published in this series may include views on policy, but the institute itself takes no institutional policy positions.

The Institute for the Study of Labor (IZA) in Bonn is a local and virtual international research center and a place of communication between science, politics and business. IZA is an independent nonprofit organization supported by Deutsche Post World Net. The center is associated with the University of Bonn and offers a stimulating research environment through its international network, workshops and conferences, data service, project support, research visits and doctoral program. IZA engages in (i) original and internationally competitive research in all fields of labor economics, (ii) development of policy concepts, and (iii) dissemination of research results and concepts to the interested public.
\end{abstract}

IZA Discussion Papers often represent preliminary work and are circulated to encourage discussion. Citation of such a paper should account for its provisional character. A revised version may be available directly from the author. 


\section{ABSTRACT}

\section{On Amenities, Natural Advantage and Agglomeration*}

A prominent feature of economic geography in America is the positive correlation amongst local incomes, housing costs and city population. This paper embeds a "black box" agglomeration economy within a more neoclassical general equilibrium model of local wages, rents and population to assess the ability of various conceptual models to predict this crosssectional variation. I use exogenous changes in housing supply to induce changes in population and examine whether the changes in rents and wages move in the same direction under neo-classical assumptions, agglomeration economies in production, congestion in production, or urbanization economies in consumption. On their own, none of these urban scale effects generate the observed pattern. All urban scale effects generate a negative correlation between rents and population. Combining natural advantage with the urban scale effects improves the models' output. It generally predicts positive correlations amongst the three variables, although some of these effects are ambiguous in the production agglomeration model. If natural advantage and housing supply constraints vary more-or-less independently, the results suggest a better fit of the data is provided by either the congestion in production or the agglomeration in consumption models. The micro-economics of such consumption-oriented agglomeration economies have received less attention than production-oriented agglomeration economies. The results of this model thus suggest that consumption-oriented agglomeration and congestion should receive more attention in the future.

JEL Classification: D5, J31, R12, R13, R23, R31

Keywords: agglomeration, urbanization economies, congestion, regional equilibrium, natural advantage, economic geography

Corresponding author:

Douglas J. Krupka

IZA

P.O. Box 7240

D-53072 Bonn

Germany

E-mail: dkrupka@iza.org

\footnotetext{
I would like to thank Kwame Donaldson, David Sjoquist, Joseph Gyourko, Michael Pflüger and Douglas S. Noonan for valuable advice, inspiration and skepticism. Any shortcomings in the paper exist despite their involvement, not because of it.
} 


\section{Introduction.}

A prominent feature of the American metropolitan system is the strong correlation amongst metropolitan average incomes, cost of living and population. Figures 1 through 3 show the relationships amongst these variables for 295 American cities in the year 2006 using data from the American Community Survey. These figures show a very tight relationship between incomes and rents, and somewhat noisier (but clearly positive) relationships between population and these two quantities. In this paper I compare the ability of various assumptions about the nature of urbanization economies to generate this pattern within a general equilibrium setting.

The past decade or so has witnessed a blossoming of research into the effects of local increasing returns on the distribution of economic activity across space. The chief goal of this literature has been to generate clustering of economic activity in cities or the clustering large cities in broader regions. While a variety of microfoundations for these agglomeration economies have been proposed, most affect the productivity of firms. Theoretically, however, there is no reason why urbanization economies could only make firms more productive (or workers more productive on the job). Amenities that affect consumers' utility might also be produced endogenously with city size. A third possible explanation for urban agglomerations could be natural advantage: large cities grow up where and when they do because of natural resources or specific aspects of the landscape, such as deep water harbors. On the other hand, larger cities might actually be less enjoyable and profitable than smaller ones, all else equal. These congestion economies could arise from overcrowded infrastructure, higher crime, or pollution, for example. While congestion externalities could not explain the existence of cities, they 
could be operating at the margin if agglomeration economies have been exhausted at the scales at which we observe most cities.

Sorting out which explanations are important and which are merely theoretically consistent is an important task for urban and regional economists and economic geographers. Knowing which of the theoretical models is the prime force that sustains cities not only offers a deeper understanding of the fundamental problems that cities form to address, but also informs the debate on regional policy, and what may be gained or lost as governments intervene in the distribution of economic activity within and across their borders.

To assess which of these broad categories of models best fits the patterns of city populations and prices mentioned in the opening paragraph, I embed a "black-box" agglomeration economy within a more neoclassical general equilibrium model similar to Roback (1982). Such a model is attractive because it naturally brings rents and wages into the same equilibrium, while it is generally the case that any location will be populated. Extensions from Krupka and Donaldson (2008) bring population explicitly into the model and thus the relationships between rents, wages and population as well as productive exogenous amenities can be examined in a relatively straightforward way. The model is also flexible enough to allow for various broad types of urbanization economies, or congestion as described above. The assumptions of the model are quite general. Residents prefer lower rents and higher wages while firms prefer areas with lower wages and rents. Amenities can enter firms' or residents' objective function in the standard way. While I do not model micro-foundations for agglomeration economies, they can be incorporated into the model by assuming firms (or residents) gain profit (or 
utility) from locating in areas with higher population. Thus, the model provides a bird's eye view of metropolitan labor and housing markets in the presence of different kinds of amenities and increasing returns.

The results show that natural advantage alone does a reasonably good job generating the desired pattern: as the prime generator of city size it creates an ambiguous but probably positive relationship between wages and rents, and between wages and population. The relationship between rents and population is positive if one is willing to make slightly stronger assumptions. Agglomeration alone generates a positive relationship between wages and population, but negative relationships between rents and the other two variables. Under the stronger assumptions made above, a combination of agglomeration and natural advantage generates a positive relationship between rents and population, but ambiguous relationships between wages and these two variables.

Interestingly, better results are available if one assumes either that cities suffer from congestion (negative agglomeration economies) or that the agglomeration economy does not increase productivity, but increases utility. These models, in combination with natural advantage, generate the strongest relationship between wages and rents, and predict a positive relationship between population and local labor and housing costs under the stronger assumptions. That congestion or consumer-related agglomeration perform better than production-oriented agglomeration is a novel result, and potentially important, as these possibilities have received much less theoretical attention and very little empirical attention. These results thus suggest that some additional investigation into these other types of local scale economies might be theoretically and empirically fruitful. 
The rest of the paper is organized as follows. Section II briefly outlines the relevant literatures. Section III lays out the basic model without any agglomeration or congestion forces. Section IV looks at the effects on the model of different kinds of returns to scale assumptions at the metropolitan level. I start with agglomeration economies in production, and then move on to congestion in production and agglomeration economies in consumption. Section V collects the results and compares them to the broad cross section patterns highlighted in figures $1-3$. Section VI concludes.

\section{Background literature.}

Determining the reasons for the dense concentration of economic activity is a primary empirical and theoretical goal of the regional economic and economic geography fields. The most obvious place to start such an examination is with the idea that these concentrations form because of desirable local characteristics which increase the productivity of firms. Such characteristic endow certain locations with a "natural advantage" over other locations. As Rosenthall and Strange (2001) comment, the idea that industrial agglomerations and therefore urban agglomerations might form in response to such natural features in the landscape has long been recognized. Ellison and Glaeser (1997) comment that "while natural advantage reasons for geographic concentration may not be exciting intellectually, they are clearly important when accounting for some of the agglomeration we observe."

Natural advantage's effect on industry-level concentration has found significant empirical support. Ellison and Glaeser (1999) and Kim (1999) find that natural 
advantage matters, at least at the state level. However, since in these papers local population, demographics and capital stocks are considered part of an area's resource endowment, the case could be made that some of these effects are actually picking up agglomeration effects, or reverse causality. Rosenthal and Strange (2001) use natural resource use intensity of industries to predict industrial concentration and find that natural resource use is positively associated with industrial concentration at the state level, but not at the county or smaller level.

As the quotation from Ellison and Glaeser (1997) attests, many economists felt unsatisfied with natural advantage as a generator of urban concentrations since in many cases the locations of cities - and their relative fortunes - seem much less deterministic. In any case, from a theoretician's point of view, such an explanation is essentially equivalent to assuming the resulting agglomeration from the beginning. Krugman (1991) presented a model hinging on imperfect competition, transportation costs and a preference for variety which generated core-periphery patterns endogenously. This model has been considerably elaborated in the New Economic Geography (NEG) literature, which was reviewed recently by Ottaviano and Thisse (2004). While the specifics of the models vary with assumptions, ${ }^{1}$ in general, firms have an incentive to locate in more populated areas because of the greater access to the consumers there, while workers wish to locate in the more populated areas because of the greater variety of low-cost products available there. While these models obviously leave a lot out, the generation of endogenous concentrations of economic activity is a major step forward.

\footnotetext{
${ }^{1}$ Pflüger and Südekum (2008) show that some of the predictions depend on functional form, and analyze the model in a more general setting. There have been many other exciting NEG papers since the 2004 review, but the general focus of the NEG literature has not changed drastically.
} 
While natural advantage stories generally rely on industry-specific effects, NEG-style agglomeration economies are economy wide.

While the NEG examines one set of possible agglomeration economies, a variety of other microfoundations for these metropolitan increasing returns have been proposed. Duranton and Puga (2004) categorize these non-NEG microfoundations as either sharing, matching or learning economies. Firms might cluster together to share indivisible inputs such as harbors, or they might share the cost advantages from a greater specialization of input providers, or they might share risk. On the other hand, firms might find clustering together increases profits because it improves the expected quality of their matches with workers, or increases the chances of making a match. Finally, a variety of learning externalities have been hypothesized in which either the generation or transfer of ideas is easier - either for firms or individuals - in more populated areas.

In this paper, I will not take a stand as to the sources of any possible increasing returns to urban scale. I consider all of the above agglomeration sources to be affecting the productivity and thus profits of individual firms. This allows the paper to take a broader view on the issue, at the cost of not being able to address the important issues of the source of these agglomeration economies. As the goal is to compare much broader categories of urban scale effects than those delineated by Duranton and Puga (2004), this seems like the appropriate choice.

While most of the sources of agglomeration effects discussed in Duranton and Puga (2004) are discussed in terms of advantages to firms, many are equally valid from the perspective of workers. Sharing indivisible inputs relates directly to the ability of large populations to sustain expensive cultural and entertainment institutions such as 
museums and professional sports teams. The importance of such local amenities has been stressed recently by Clark (2003). Consumers in larger urban areas are also sharing the gains to greater variety of goods and services (Florida 2002). They share the gains to a larger variety of public service levels alla Tiebout, and even in terms of the kinds of friends and lifestyle they can have (Fischer, 1975, discusses this in terms of a greater variety of subcultures in larger cities). Residents of large areas also share risk in terms of the availability and quality of leisure activities. ${ }^{2}$ Large urban agglomerations can also increase the expected probability and quality of matching in terms of the marriage market, which Costa and Kahn (2000) discuss. The larger variety of public service regimes and subcultures discussed above could also be interpreted in terms of providing a better expected quality of match to one's preferences. With regard to learning, the larger flows of information in cities, and the greater quantity (as well as variety and perhaps quality) of group activities could allow faster learning about how to get the most utility out of leisure activities. These potential consumption-oriented urban agglomeration effects range from the trivial to the profound, but they have received less attention from urban economists and economic geographers. In this paper I will examine the effects of such agglomeration in consumption economies and compare their effects with other types of agglomeration.

Although recent attention has been focused primarily on increasing returns to urban scale, an older literature - and indeed much regional policy - was more concerned about the possibility that larger urban scale decreased utility or productivity. Tolley (1974) and Tolley and Crihfield (1987) discuss this issue in great detail, while Blomquist

\footnotetext{
${ }^{2}$ At least in theory, residents of Chicago have a higher chance of a local team winning the World Series than residents of Cincinnati or St. Louis.
} 
et al. (1988) allow for such effects. While the focus of these papers on congestion effects is somewhat jarring given the recent spate of research on the benefits of urban concentration, it should be taken seriously. First, it is not unreasonable to believe that residents of larger cities may face more negative externalities - such as air pollution, traffic congestion and crime - than smaller cities. While Tolley (1974) is most concerned about these externalities when they are not internalized, even if they are internalized they will affect regional populations and prices. Second, while these negative scale economies have received less attention, they represent the "received wisdom" from the planning and policy world of the pre-Krugman era. While it seems odd that there would be cities at all without some form of local increasing returns, it is quite possible that those returns could be exhausted and that congestion economies dominate at the margin. The model in this paper is flexible enough to easily allow for such congestion economies, so that I will be able to compare the effects of agglomeration to the effects of congestion on urban populations and prices.

Finally, one of the novel features of the model in this paper is that firms and consumers are heterogeneous with regards to a local attachment to their home area. Tabuchi and Thisse (2002) started research along these lines in a model which combines heterogeneous consumers and a natural amenity in a NEG framework. Another important, but less novel feature is that increased population in an area increases land prices through a positively sloped supply of housing. Tabuchi (1998) and Ottaviano, Tabuchi and Thisse (2002) leave out heterogeneity or amenities, but include increasing land prices in their models. Both sets of assumptions generate some moderation in the severe core-periphery results of the NEG model. I am not aware of any papers that 
include amenities and heterogeneity along with increasing land prices in a NEG model.

The importance of local housing supply conditions has been discussed recently in Glaeser et al. (2005, 2006), Glaeser and Gyourko (2005), Gyourko et al. (2006) and Gyourko and Saiz (2006). This paper will combine all three factors (amenities, increasing local housing prices and heterogeneity), and add firm heterogeneity to the mix ${ }^{3}$ while remaining agnostic about the microfoundations (and indeed the direction) of any possible effects of urban scale on individuals' objective functions.

\section{Model set-up.}

I assume that there is a continuum of firms and workers, each of measure one. Residents have utility functions and firms have production functions which generate indirect utility functions $(v)$ and profit functions $(\pi)$ which depend on rents $(r)$, wages $(w)$ and a local characteristic, or amenity $(A)$. Firm profits and resident utility depend negatively on rents, while higher wages increase utility and decrease profits. The effects of amenities on utility and profits could be anything, but to motivate the "natural advantage" interpretation of amenities, I will generally take the amenity's effect on utility to be negligible and its effect on profits to be strong and positive. In symbols:

$v(r, w ; A), \quad v_{r}<0, v_{w}>0, v_{A} \approx 0$

$\pi(r, w ; A), \quad \pi_{r}<0, \pi_{w}<0, \pi_{A} \gg 0$

While rents and wages will be determined endogenously in the system, amenities will be set exogenously. Firms and residents choose a bundle of rents, wages and amenities through location choice. Each city is represented by a local combination of rents and

\footnotetext{
${ }^{3}$ Firm heterogeneity is addressed in its own literature, and has been incorporated into a core-periphery model by Baldwin and Okubo (2006).
} 
wages (set endogenously), and amenities and housing supply shift factor ( $C$, which will be introduced below) which are set exogenously.

The first condition that must be satisfied for the system to be in equilibrium is that no firm or resident should wish to move. Whether a firm or resident would wish to move from a city will depend on the amenities at that location, the rents, the wages and the costs of leaving the city, which will include physical moving costs that vary across individuals and the sacrifice of returns to local social and professional networks and local knowledge (as in Krupka 2007). Firms and residents are thus modeled as having individual attachment or attraction to their home city. The spatial equilibrium holds only if every agent's economic profit from locating in the city exceeds zero. Otherwise firms or residents will migrate and the rents and wages will need to adjust. In symbols, 1) $\quad \pi(r, w ; A)-\underline{\pi} \geq \varphi_{j} \sim F(\cdot)$. 2) $\quad v(r, w ; A)-\underline{v} \geq \gamma_{i} \sim G(\cdot)$. In equation (1), $\underline{\pi}$ is the reservation profit, or the profit the firm could make in some other city. A similar interpretation of $\underline{v}$ pertains in equation (2) in terms of utility. These reservation profits and utilities can be set to zero at no loss of generality. The Greek letters $\varphi$ and $\gamma$ represent the gains to moving (or negative of the local attachment) and are distributed according to the $\mathrm{CDFs} F($.$) and G($.), respectively. Assuming the reservation utilities $(\underline{v})$ and profits $(\underline{\pi})$ are zero, the population of firms and residents willing to locate in a given city can be derived by plugging the profit and indirect utility functions into the distribution functions of the local attachments so that the measure of firms in a city is $F(\pi(r, w ; A))$ and the measure of residents is $G(v(r, w ; A))$. One need not make any assumptions about $F($.$) or G($.$) beyond those implied by the definition of a CDF.$ 
For the metropolitan system to be in equilibrium, two additional conditions must hold. These are that wages and rents adjust such that the supply and demand for labor and housing are equal. In the labor market, we can assume for simplicity that each firm demands and each resident supplies one unit of labor. ${ }^{4}$ Labor market equilibrium can thus be characterized as in equation (3):

$$
G(v(r, w ; A))-F(\pi(r, w ; A))=0 .
$$

Equation (3) implicitly defines wage as a function of amenities and rents. I denote this function as $w(r ; A)$. The effects of rents and amenities on wages (holding the other constant) are obtained through the implicit function rule:

$$
\begin{aligned}
& w_{r}=\frac{F^{\prime} \pi_{r}-G^{\prime} v_{r}}{G^{\prime} v_{w}-F^{\prime} \pi_{w}} \\
& w_{A}=\frac{F^{\prime} \pi_{A}-G^{\prime} v_{A}}{G^{\prime} v_{w}-F^{\prime} \pi_{w}} .
\end{aligned}
$$

The sign of these partial effects on wage is ambiguous in general. However, for the case of amenities as "natural advantage" (with $v_{A}$ close to zero and $\pi_{A}$ much greater than zero) being used here, the effect of amenities on wages can be signed as positive, holding rents constant.

With the wage function $w(r ; A)$, it is also possible to derive the function of firm and residential population in a city, which will depend only on rents and amenities. For firms, this function is:

4) $\quad \Sigma(r ; A)=F(\pi(r, w(r ; A) ; A))$.

\footnotetext{
${ }^{4}$ This assumption can be relaxed without any qualitative change to the results. The relaxation of this assumption is discussed at somewhat greater length in Krupka and Donaldson (2008).
} 
The effects of rents and amenities on firm population is $\Sigma_{r}=F^{\prime}\left(\pi_{r}+\pi_{w} w_{r}\right)$ and $\Sigma_{A}=$ $F^{\prime}\left(\pi_{A}+\pi_{w} w_{A}\right)$, respectively. ${ }^{5}$ For residents the function is:

5) $\Omega(r ; A)=G(v(r, w(r ; A) ; A))$.

The effects of rents and amenities on residential population is $\Omega_{r}=G^{\prime}\left(v_{r}+v_{w} w_{r}\right)$ and $\Omega_{A}=$ $G^{\prime}\left(v_{A}+v_{w} w_{A}\right)$, respectively. Because equation (3) must hold for any rent level and any amenity level, I will often be able to make use of the facts that $\Sigma=\Omega$, that $\Omega_{r}=\Sigma_{r}$ and that $\Omega_{A}=\Sigma_{A}$. Although it is not immediately obvious from the equations, it is worth pointing out that $\Omega_{r}=\Sigma_{r}<0$ because both firms and residents would prefer a location with lower rents to one with higher rents, all else equal. An exogenous increase in rents will therefore drive both firm and residential population down, but have an ambiguous effect on wages. Similarly, it can be shown that a "natural advantage" amenity will have a positive direct effect on population $\left(\Omega_{A}=\Sigma_{A}>0\right)$.

Before closing the model by invoking housing market equilibrium, a brief graphical exposition the theory to this point will be of use later when we start allowing for various agglomeration and congestion effects. Figures $4 \mathrm{a}$ and $4 \mathrm{~b}$ show the distribution of indifference curves in rent-wage space under two different assumptions. In 4a, individual heterogeneity is assumed away, as in the classic model of Roback (1982). In this model where everyone is the same, rent and wages are uniquely determined by the level of amenities, and population is set by dividing the amount of available land in a city by the per capita demand for land. In this set up, everyone is

\footnotetext{
${ }^{5}$ It bears emphasis that, although the value of $F^{\prime}$ can vary with the value of profits at which the derivative is evaluated, in these partial effects the term enters only as a multiplier of the terms in parentheses. The same statement applies to the interpretation of $G^{\prime}$ below.
} 
indifferent between any two cities, because wages and rents adjust so that there are no gains to migration. Costless migration guarantees this indifference.

In figure $4 \mathrm{~b}$, we see the situation is changed when migration costs vary across individuals. Given the assumptions of the model (most importantly, that people and firms all prefer lower rents all else equal), the indifference curve (between a given city and the next best city) will depend on the heterogeneous local attachment. To the left, with low rents, many firms and people will be willing to live in the city because inequalities (1) and (2) will hold for a large proportion of them. As rents increase, fewer and fewer individual firms and residents will find the amenity-rent-wage combination satisfactory enough to prevent moving out of the city, and population decreases. Figure 4b highlights a few level curves out of the $F($.$) and G($.$) distribution, but in actuality, the$ inequalities describe a surface in rent-wage-population space (this surface will change when amenities are changed). In contrast to the Roback model represented in figure 4a, the setting of wages and rents is not straight forward.

To generate the wage function, we impose labor market equilibrium where labor supply (the population of residents) equals labor demand (the population of firms). This is essentially the intersection of the two surfaces described above. Figure 5 shows the resulting wage function. The slope of this wage function $\left(w_{r}\right)$ will become important below. In a three dimensional graph, the population of firms and residents could be read off of the third axis, which is analytically accomplished by plugging the rent and amenity levels and wage function into the profit and indirect utility functions ( $\pi$ and $v)$ and plugging the resulting functions of $r$ and $A$ into the CDFs of the local attachments for the population of firms and residents. However, the imposition of equilibrium in the labor 
market does not tell us which of the possible rents, and thus wages and thus populations will be realized in the city in question for a given level of amenities $(A)$.

Equation (3) allows local wages to adjust to clear the local labor market. The other local price that adjusts is the local housing cost, or rent. Local rents adjust so that the supply of housing equals the demand for housing:

6) $\quad S(r ; C)-\Omega(r ; A) D(r, w(r ; A))=0$.

New in equation (6) are a housing supply function $(S)$ and a per capita housing demand function $(D)$. Housing supply is assumed to be increasing in rents and decreasing in the housing supply constraint or cost shifter, $C\left(S_{r}>0, S_{C}<0\right){ }^{6}$ The housing supply shift factor will later allow me to generate exogenous changes in city population to assess the effects of such increases on rents and wages. Housing demand represents the combined demand for space that each worker/resident generates through their demand for space at home and at work. In essence, it is the demand for space for each resident and the firm which employs him. ${ }^{7}$ This per capita demand for housing is assumed to increase with wages $\left(D_{w}>0\right)$, decrease with rents holding wages constant $\left(D_{r}<0\right)$, and decrease with rents when wages adjust $\left(D_{r}+D_{w} w_{r}<0\right)$.

Equation (6) implicitly defines rents as a function of amenities and housing supply shifters. Since wages and populations are functions only of rents and amenities, equation (6) closes the model. The general equilibrium effect of changes in housing supply and "natural advantage" amenities on rents, wages and population are thus:

$$
\frac{d r}{d C}=\frac{-S_{C}}{S_{r}-\Omega_{r} D-\Omega\left(D_{r}+D_{w} w_{r}\right)}
$$

\footnotetext{
${ }^{6}$ The housing supply shift factor is discussed more thoroughly in Krupka and Donaldson (2008). Here, it suffices to say that these shifts could arise due to local geographical, geological or regulatory conditions.

${ }^{7}$ Modeling the housing/space demands of firms and residents separately is possible, but not enlightening.
} 
7b) $\frac{d w}{d C}=w_{r} \frac{d r}{d C}$

7c) $\frac{d \Omega}{d C}=\Omega_{r} \frac{d r}{d C}=\Sigma_{r} \frac{d r}{d C}=\frac{d \Sigma}{d C}$

7d) $\quad \frac{d r}{d A}=\frac{\Omega_{A} D+\Omega D_{w} w_{A}}{S_{r}-\Omega_{r} D-\Omega\left(D_{r}+D_{w} w_{r}\right)}$

7e) $\quad \frac{d w}{d A}=w_{A}+w_{r} \frac{d r}{d A}$

7f) $\frac{d \Omega}{d A}=\Omega_{A}+\Omega_{r} \frac{d r}{d A}=\Sigma_{A}+\Sigma_{r} \frac{d r}{d A}=\frac{d \Sigma}{d A}$

With these results in hand, it is straightforward to see how well this purely neoclassical framework does at generating the three relationships among city wages, rents and population that we observe in the data. Population can be changed exogenously by changing $C$ to allow for more or less people to live in the city. Tightening the supply constraint will increase rents (the denominator in $7 \mathrm{a}$ and $7 \mathrm{~d}$ is positive), have an ambiguous effect on wages ( $w_{r}$ is ambiguous in $\left.7 \mathrm{~b}\right)$ and decrease population $\left(\Omega_{r}\right.$ and $\Sigma_{r}$ are negative in 7c). Thus, the pure neoclassical model predicts no correlation between wages and the other two local characteristics, and a negative correlation between population and rents. These predictions are not consistent with observed patterns.

In the neo-classical setting, natural advantage does a somewhat better job generating the observed correlations. An amenity that increases profits but does not affect utility will increase rents unambiguously ( $w_{A}$ and $\Omega_{A}$ will both be positive in $\left.7 \mathrm{~d}\right)$. There is some ambiguity in the general equilibrium effect on wages (7e) because the clearly positive direct effect of amenities on wages $\left(w_{A}\right)$ is combined with an ambiguous indirect effect on wages through rents $\left(w_{r} \frac{d r}{d A}\right)$. If the partial effect of rents on wages is 
either positive or small in magnitude, the total effect of natural advantage on wages will be positive. If this is the case, the neo-classical model with natural advantage will predict a positive correlation between rents and wages, although that correlation might be weak. Finally, the general equilibrium effect of natural advantage on population (7f) is at first examination ambiguous. The positive direct effect of the natural advantage amenity on population $\left(\Omega_{A}\right)$ is balanced by the negative effect of amenities on population through rents $\left(\Omega_{r} \frac{d r}{d A}\right)$. Because $\frac{d r}{d A}$ is actually a function of both $\Omega_{A}$ and $\Omega_{r}$, it is difficult to break this ambiguity by choosing particular values of more fundamental quantities because those things that tend to make the positive components of (7f) larger in magnitude will also tend to make the negative components large in magnitude as well. Thus, while natural advantage somewhat predicts one of the three positive correlations (between wages and rents) it does not predict the other two correlations (between wages or rents and population) that we observe in the actual data. ${ }^{8}$ The apparent ambiguity of the natural advantage effect on populations will be something we return to later after exploring different assumptions about the effects of urban scale on profits and utility.

\section{Urban scale effects.}

The simple neoclassical construction of a general equilibrium model in section III did not generate the pattern of rents, wages and populations we observe. While naturally

\footnotetext{
${ }^{8}$ If the partial effect of rents on wages were negative, this would suggest a positive correlation between wages and population because both general equilibrium effects (of natural advantage) would share the $d r / d A$ term multiplied by a negative number. However, this would weaken or negate the positive correlation between wages and rents. Similarly, if the effect of natural advantage on rents were very small, the correlation between wages and population would be stronger, but the correlation between rents and these quantities would be smaller. So, to the extent that the pure natural advantage effect can generate the second correlation, it looses its ability to generate the first correlation.
} 
advantaged areas will have higher rents and wages, the model does not appear to suggest that these exogenous increases in productivity will increase populations. This leads to a natural question of whether the causation might run in the other direction. Might higher population cause higher productivity? In this section, I embed a kind of "black box" agglomeration technology into the model from section III to assess whether an agglomeration effect in production will generate the three-fold correlation between rents, wages and population. This section also generates results for agglomeration diseconomies, or congestion effects, and for agglomeration economies in consumption. The results from the different models will be compared in the next section.

\section{A. Agglomeration economies in production.}

While the literature on agglomeration economies has been very rigorous and drawn many useful distinctions between various sources of agglomeration, the most influential theories have all posited some form of production-oriented agglomeration. In this paper, I remain agnostic about the foundations of any agglomeration effects. Instead, I assume that, in the end, these agglomeration effects will make firms more productive, and thus increase profits for any given level of rents, wages and non-agglomeration amenities. In symbols, the profit function for firms in the presence of agglomeration economies in production $(A P)$ is:

$\pi\left(r, w, u_{A P} ; A\right), \quad u_{A P}=u_{A P}(\Sigma), u_{A P}^{\prime}>0, \pi_{u}>0$.

In words, the profits of a firm will now depend positively on the new urbanization variable $\left(u_{A P}\right)$, which is increasing in the population of firms $(\Sigma)$ in the city. The indirect utility function of the residents is not affected by these agglomeration effects. 
With this minor modification to the profit function made, we can then proceed with the solution of the model as in section III, with one more consideration. Referring back to the partial effects of rents and amenities on wages, the size and signs of these effects depended on two factors: the relative effect of rents or amenities on profits and utility (the $\pi$ and $v$ terms), and the population-response of firms and residents to changes in profits and utility $\left(F^{\prime}\right.$ and $\left.G^{\prime}\right)$. Because profits are now a function of population of firms, this result needs to be modified.

Of interest is the effect of a change in some factor $(r$ or $A)$ on the population of firms, given the effect of population of firms on the urbanization economy $\left(u_{A P}\right)$ and its effect back on profits. The effect of such a factor on population will thus be made of a direct effect (through the profit function) and an indirect effect through population itself in the following manner:

8) $\frac{\partial \Sigma}{\partial x}=F^{\prime} \pi_{x}+F^{\prime} \pi_{u} u_{A P}^{\prime} \frac{\partial \Sigma}{\partial x}$,

where $x$ could be either rent or amenities. The first term in equation (8) is the direct effect on population through profits: the effect of $x$ on profits times the effect of profits on the population of firms. The second term is the indirect or "second round" effect that $x$ has on population, times population's effect on agglomeration economies, times agglomeration's effect on profits times profit's effect on the population of firms. Rearranging terms, we get the effect of some factor $x$ on population in the presence of reinforcing agglomeration economies:

9) $\frac{\partial \Sigma}{\partial x}=\frac{F^{\prime}}{1-F^{\prime} \pi_{u} u_{A P}^{\prime}} \pi_{x}$. 
Again, in this model $x$ can stand in for either rents or amenities. While this derivation is somewhat informal, the same result is available via a more involved application of the implicit function rule in a multi-equation setting. This result implies one major change in the output of the model vis-à-vis the neoclassical model from section III. Whereas the neoclassical model often included the term $F^{\prime}$ in results (such as $w_{r}, w_{A}, \Sigma_{r}$ and $\Sigma_{A}$ ), in the model with agglomeration this term must be replaced with $F^{\prime} /\left(1-F^{\prime} \pi_{u} u_{A P}^{\prime}\right)$. Once this change has been made, the rest of the model can be solved in the same way as in the neoclassical case by imposing labor market equilibrium to derive wage and population functions, then imposing housing market equilibrium to identify local rents, wages and populations conditional on housing supply constraints and amenities.

Before moving onto those results, a brief graphical presentation of the model with agglomeration economies may be useful. Figure 6 reproduces figure 5 with the old level curves and wage function reproduced for comparison with dashed lines. Because higher population of firms increases profits, the level curves for firms will change in the presence of agglomeration effects. Moving from right to left along the old wage curve $(w(r ; A))$, the lower rents were associated in the neoclassical model with higher populations. But, because higher populations are essentially an additional productive amenity for firms, more firms will be willing to locate in the city as rents decrease. The level curve representing the same proportion of firms will now move slightly to the right; the same proportion of firms will be willing to pay higher rents or wages in order to gain access to the city's amenities and population/agglomeration economies. As rents get lower and population gets larger, this additional agglomeration effect will become more powerful, so the shift in each level curve becomes greater. In terms of the three- 
dimensional surface that these level curves describe, agglomeration makes it slope more steeply with respect to rents. Labor market equilibrium thus changes, and the new wage function $\left(w\left(r, u_{A P} ; A\right)\right)$ will tend to be more negatively sloped than the old one.

Technically, it is possible for the agglomeration economies to be so strong that all the level curves stack up on one another and the slope of the population function with respect to rent becomes undefined (analytically, this happens when $1=F^{\prime} \pi_{u} u_{A P}^{\prime}$ ) or even becomes positively sloped (when $1<F^{\prime} \pi_{u} u_{A P}^{\prime}$ ). However, I assume that - while agglomeration economies exist - they are not strong enough to make firms appear to "like" higher rents.

The addition of agglomeration economies changes the intermediate functions of the model's solution. The new intermediate or partial functions are modified in the following way

$$
\begin{aligned}
& w_{r}^{A P}=\frac{F^{\prime} \pi_{r}-\left(1-F^{\prime} \pi_{u} u_{A P}^{\prime}\right) G^{\prime} v_{r}}{\left(1-F^{\prime} \pi_{u} u_{A P}^{\prime}\right) G^{\prime} v_{w}-F^{\prime} \pi_{w}} \\
& w_{A}^{A P}=\frac{F^{\prime} \pi_{A}-\left(1-F^{\prime} \pi_{u} u_{A P}^{\prime}\right) G^{\prime} v_{A}}{\left(1-F^{\prime} \pi_{u} u_{A P}^{\prime}\right) G^{\prime} v_{w}-F^{\prime} \pi_{w}}
\end{aligned}
$$

In comparison to the neo-classical model, the model with agglomeration generates a wage function that is more likely negatively-sloped with respect to rents $\left(w_{r}^{A P}<w_{r}\right)$, but more positively-sloped with respect to productive amenities $\left(w_{A}^{A P}>w_{A}>0\right)$. The change in the partial effects of rents on amenities on firm population is also pronounced:

$$
\begin{aligned}
& \Sigma_{r}^{A P}=\frac{F^{\prime}}{1-F^{\prime} \pi_{u} u_{A P}^{\prime}}\left(\pi_{r}+\pi_{w} w_{r}^{A P}\right) \\
& \Sigma_{A}^{A P}=\frac{F^{\prime}}{1-F^{\prime} \pi_{u} u_{A P}^{\prime}}\left(\pi_{A}+\pi_{w} w_{A}^{A P}\right)
\end{aligned}
$$


The effects of the agglomeration economy on residential population are more subtle:

$$
\begin{aligned}
& \Omega_{r}^{A P}=G^{\prime}\left(v_{r}+v_{w} w_{r}^{A P}\right) \\
& \Omega_{A}^{A P}=G^{\prime}\left(v_{A}+v_{w} w_{A}^{A P}\right)
\end{aligned}
$$

Despite the modifications, labor market equilibrium requires (and it can be shown) that $\Omega_{r}^{A P}=\Sigma_{r}^{A P}$ and that $\Omega_{A}^{A P}=\Sigma_{A}^{A P}$. The first of these pairs can be shown to be negative and the second to be positive.

Keeping these modifications in mind, the final output of the model with agglomeration is very similar to that without.

10a) $\frac{d r}{d C}=\frac{-S_{C}}{S_{r}-\Omega_{r}^{A P} D-\Omega^{A P}\left(D_{r}+D_{w} w_{r}^{A P}\right)}$

10b) $\frac{d w^{A P}}{d C}=w_{r}^{A P} \frac{d r}{d C}^{A P}$

10c) $\frac{d \Omega^{A P}}{d C}=\Omega_{r}^{A P} \frac{d r}{d C}^{A P}=\Sigma_{r}^{A P} \frac{d r}{d C}^{A P}=\frac{d \Sigma^{A P}}{d C}$

10d) $\frac{d r}{d A}{ }^{A P}=\frac{\Omega_{A}^{A P} D+\Omega^{A P} D_{w} w_{A}^{A P}}{S_{r}-\Omega_{r}^{A P} D-\Omega^{A P}\left(D_{r}+D_{w} w_{r}^{A P}\right)}$

10e) $\quad \frac{d w^{A P}}{d A}=w_{A}^{A P}+w_{r}^{A P} \frac{d r}{d A}^{A P}$

10f) $\frac{d \Omega^{A P}}{d A}=\Omega_{A}^{A P}+\Omega_{r}^{A P} \frac{d r}{d A}^{A P}=\Sigma_{A}^{A P}+\Sigma_{r}^{A P} \frac{d r}{d A}^{A P}=\frac{d \Sigma^{A P}}{d A}$

Examining these results, a tightening of the housing supply constraint will increase rents (10a), have an ambiguous but probably negative effect on wages (10b) and a negative effect on population (10c). The housing supply constraint, $C$, is the primary lever in this model to induce exogenous changes in population. What these results suggest is that 
agglomeration effects alone will not generate the three positive correlations between rents, wages and city population. Agglomeration will likely generate a negative correlation between rents and wages and between rents and population, and a positive correlation between wages and population.

Agglomeration forces in combination with natural advantage will have different effects. In this setting with agglomeration, natural advantage will increase rents (10d), have an ambiguous effect on wages (10e), and an ambiguous effect on population (10f). Thus, natural advantage combined with agglomeration in production eliminates the negative correlations between rents and wages and between rents and population, and retains a probable positive correlation between population and wages.

\section{B. Congestion in production.}

We now can turn our attention to the predictions of the model in the presence of agglomeration diseconomies, or congestion effects. The model is easily modified to allow for this possibility. The new profit function for firms facing congestion externalities $(\mathrm{Co})$ looks the same as in the case of agglomeration, but the urban scale effects are now negative:

$\pi\left(r, w, u_{C o} ; A\right), \quad u_{C o}=u_{C o}(\Sigma), u_{C o}^{\prime}<0, \pi_{u}>0$.

This change is shown graphically in figure 7 . Figure 7 presents in dashed lines the wage function from the neoclassical model of figure 5. However, in contrast to the agglomeration model, the increases in population that occur as one moves leftward along the wage curve are now a disamenity to firms (it decreases their productivity), driving their willingness to locate in the city down. In terms of the surface that these level curves represent, it is becoming less negatively sloped with respect to rent. These changes imply 
that after the imposition of labor market equilibrium, the wage function is more likely to be positively sloped than in the neo-classical or agglomeration cases.

Propagating this change through the intermediate results in the model we arrive at these new partial effects of rents and amenities on wages:

$$
\begin{gathered}
w_{r}^{C o}=\frac{F^{\prime} \pi_{r}-\left(1-F^{\prime} \pi_{u} u_{C o}^{\prime}\right) G^{\prime} v_{r}}{\left(1-F^{\prime} \pi_{u} u_{C o}^{\prime}\right) G^{\prime} v_{w}-F^{\prime} \pi_{w}} \\
w_{A}^{C o}=\frac{F^{\prime} \pi_{A}-\left(1-F^{\prime} \pi_{u} u_{C o}^{\prime}\right) G^{\prime} v_{A}}{\left(1-F^{\prime} \pi_{u} u_{C o}^{\prime}\right) G^{\prime} v_{w}-F^{\prime} \pi_{w}}
\end{gathered}
$$

The change is visually subtle: the $A P$ index has been changed to $C o$. However, the changes in functional form are important. As mentioned earlier, $w_{r}^{A P}<w_{r}<w_{r}^{C o}$. So $w_{r}^{C o}$ is likely positive. Also, for natural advantage type productive amenities, $w_{A}^{A P}>w_{A}>w_{A}^{C o}>0$.

The partial effects of rents or amenities on firm population are also visually similar to those quantities in the $A P$ model:

$$
\begin{aligned}
& \Sigma_{r}^{C o}=\frac{F^{\prime}}{1-F^{\prime} \pi_{u} u_{C o}^{\prime}}\left(\pi_{r}+\pi_{w} w_{r}^{C o}\right) \\
& \Sigma_{A}^{C o}=\frac{F^{\prime}}{1-F^{\prime} \pi_{u} u_{C o}^{\prime}}\left(\pi_{A}+\pi_{w} w_{A}^{C o}\right)
\end{aligned}
$$

The effects of the agglomeration economy on residential population are even more subtle:

$$
\begin{aligned}
& \Omega_{r}^{C o}=G^{\prime}\left(v_{r}+v_{w} w_{r}^{C o}\right) \\
& \Omega_{A}^{C o}=G^{\prime}\left(v_{A}+v_{w} w_{A}^{C o}\right)
\end{aligned}
$$

It is still the case that $\Omega_{r}^{C o}=\Sigma_{r}^{C o}<0$ and that $\Omega_{A}^{C o}=\Sigma_{A}^{C o}>0$. In comparison to the agglomeration model, the partial effect of rent on population will be larger (less negative) and the partial effect of productive amenities on population will be smaller. 
Plugging these new partial effects into the general equilibrium effects of changes in rents and amenities yields the following results, which are identical to those in equations 10 , save for the superscripts.

11a) $\frac{d r}{d C}{ }^{C o}=\frac{-S_{C}}{S_{r}-\Omega_{r}^{C o} D-\Omega^{C o}\left(D_{r}+D_{w} w_{r}^{C o}\right)}$

11b) $\frac{d w^{C o}}{d C}=w_{r}^{C o} \frac{d r^{C o}}{d C}$

11c) ${\frac{d \Omega^{C o}}{d C}}^{C o}=\Omega_{r}^{C o} \frac{d r}{d C}^{C o}=\Sigma_{r}^{C o} \frac{d r}{d C}^{C o}={\frac{d \Sigma^{C o}}{d C}}^{C o}$

11d) $\frac{d r}{d A}{ }^{C o}=\frac{\Omega_{A}^{C o} D+\Omega^{C o} D_{w} w_{A}^{C o}}{S_{r}-\Omega_{r}^{C o} D-\Omega^{C o}\left(D_{r}+D_{w} w_{r}^{C o}\right)}$

11e) $\frac{d w^{C o}}{d A}=w_{A}^{C o}+w_{r}^{C o} \frac{d r^{C o}}{d A}$

11f) ${\frac{d \Omega^{C o}}{d A}}^{C o}=\Omega_{A}^{C o}+\Omega_{r}^{C o} \frac{d r}{d A}^{C o}=\Sigma_{A}^{C o}+\Sigma_{r}^{C o} \frac{d r}{d A}^{C o}={\frac{d \Sigma^{C o}}{d A}}^{C o}$

With congestion, an exogenous decrease in housing supply will increase rents (11a), increase wages $\left(11 \mathrm{~b}\right.$, assuming that $\left.w_{r}^{C o}>0\right)$ and decrease population $(11 \mathrm{c})$. These results suggest a positive correlation between wages and rents, but a negative relationship between these local prices and population. In the presence of congestion, cities with more "natural advantage" will have higher rents (11d) and higher wages (11e), but the effect of natural advantage on population is still ambiguous (11f).

\section{Agglomeration economies in consumption.}

The final modification we make to the model is to allow the agglomeration or urbanization effects of city scale to affect consumers instead of producers. In terms of 
the model presented here, we can allow for such effects by making the urbanization economy affect residents' utility (as opposed to affecting firms' profits as in part IV.A). Therefore, in the agglomeration in consumption $(A C)$ model, the profit function of the firms will be the same as in section III, but the indirect utility function will be modified as follows:

$v\left(r, w, u_{A C} ; A\right) \quad u_{A C}=u_{A C}(\Omega), u_{A C}^{\prime}>0, v_{u}>0$.

This change is represented graphically in figure 8 , where the agglomeration in consumption effect makes consumers willing to pay higher rents as population goes up because the higher population increases their utility. This makes the wage curve more positively sloped, and makes the population function steeper with respect to rents.

Analytically, this change in the model means that the effect of changes in profits on firm population goes back to $F^{\prime}$ (as in section III), and that the effect of utility on residential population must be changed to reflect the consumption agglomeration effects. In this context, the term $G^{\prime} /\left(1-G^{\prime} v_{u} u_{A C}^{\prime}\right)$ must be substituted for $G^{\prime}$, relative to section III. ${ }^{9}$ This results in new partial effects of rents and amenities on the wage function:

$$
\begin{aligned}
& w_{r}^{A C}=\frac{\left(1-G^{\prime} v_{u} u_{A C}^{\prime}\right) F^{\prime} \pi_{r}-G^{\prime} v_{r}}{G^{\prime} v_{w}-\left(1-G^{\prime} v_{u} u_{A C}^{\prime}\right) F^{\prime} \pi_{w}} \\
& w_{A}^{A C}=\frac{\left(1-G^{\prime} v_{u} u_{A C}^{\prime}\right) F^{\prime} \pi_{A}-G^{\prime} v_{A}}{G^{\prime} v_{w}-\left(1-G^{\prime} v_{u} u_{A C}^{\prime}\right) F^{\prime} \pi_{w}}
\end{aligned}
$$

As in the congestion case, the rental wage effect is larger than the neoclassical rental wage effect, but the amenity effect is smaller. The partial effects of rents and amenities on firm population then become:

\footnotetext{
${ }^{9}$ As in the $A P$ model, I assume that $1-G^{\prime} v_{u} u_{A C}>0$, or that agglomeration is not strong enough to make residents appear to "like" higher rents.
} 


$$
\begin{aligned}
& \Sigma_{r}^{A C}=F^{\prime}\left(\pi_{r}+\pi_{w} w_{r}^{A C}\right) \\
& \Sigma_{A}^{A C}=F^{\prime}\left(\pi_{A}+\pi_{w} w_{A}^{A C}\right)
\end{aligned}
$$

The partial effects of rents and amenities on residential population become:

$$
\begin{aligned}
& \Omega_{r}^{A C}=\frac{G^{\prime}}{\left(1-G^{\prime} v_{u} u_{A C}^{\prime}\right)}\left(v_{r}+v_{w} w_{r}^{A C}\right) \\
& \Omega_{A}^{A C}=\frac{G^{\prime}}{\left(1-G^{\prime} v_{u} u_{A C}^{\prime}\right)}\left(v_{A}+v_{w} w_{A}^{A C}\right)
\end{aligned}
$$

The partial effect of rents on firm or residential population will be larger (less negative) than the same effect in the neo-classical or agglomeration in production cases, but the partial effect of amenity on population will be smaller (less positive).

Taking these changes, the general equilibrium effects of supply constraints and natural advantage on rents wages and population are easily expressed:

12a) $\frac{d r^{A C}}{d C}=\frac{-S_{C}}{S_{r}-\Omega_{r}^{A C} D-\Omega^{A C}\left(D_{r}+D_{w} w_{r}^{A C}\right)}$

12b) $\frac{d w^{A C}}{d C}=w_{r}^{A C} \frac{d r}{d C}$

12c) ${\frac{d \Omega^{A C}}{d C}}^{A C} \Omega_{r}^{A C} \frac{d r}{d C}^{A C}=\Sigma_{r}^{A C} \frac{d r}{d C}^{A C}=\frac{d \Sigma^{A C}}{d C}$

12d) $\frac{d r}{d A}{ }^{A C}=\frac{\Omega_{A}^{A C} D+\Omega^{A C} D_{w} w_{A}^{A C}}{S_{r}-\Omega_{r}^{A C} D-\Omega^{A C}\left(D_{r}+D_{w} w_{r}^{A C}\right)}$

12e) $\frac{d w^{A C}}{d A}=w_{A}^{A C}+w_{r}^{A C} \frac{d r^{A C}}{d A}$

12f) ${\frac{d \Omega^{A C}}{d A}}^{A C} \Omega_{A}^{A C}+\Omega_{r}^{A C} \frac{d r}{d A}^{A C}=\Sigma_{A}^{A C}+\Sigma_{r}^{A C} \frac{d r}{d A}^{A C}=\frac{d \Sigma^{A C}}{d A}$ 
The results are qualitatively identical to those for the case of congestion. A decrease in the housing supply leads to higher rents (12a) and wages (12b), but lower populations (12c), retaining the negative correlation between population and the two local prices. Natural advantage combined with agglomeration in consumption leads to higher rents (12d) and wages (12e), but the effect on population is again indeterminate (12f).

\section{Comparing models.}

In this section I collect the results from the various models of urban scale effects and compare them. In doing so, the relative sizes of the partial effects of rent and a natural advantage amenity on wages and populations bear repeating.

13a) $\quad w_{r}^{A P}<w_{r}<w_{r}^{C o} \approx w_{r}^{A C}$

13b) $\quad w_{A}^{A P}>w_{A}>w_{A}^{C o} \approx w_{A}^{A C}>0$

$w_{r}^{C o}=w_{r}^{A C}$ and $w_{A}^{C o}=w_{A}^{A C}$ whenever $1-G^{\prime} v_{u} u_{A C}^{\prime}=1 /\left(1-F^{\prime} \pi_{u} u_{C o}^{\prime}\right)$. This represents a

situation where the congestion effect and the consumer agglomeration effects are of equal "intensity." If that is the case, then the relative size of the partial effects of rents and amenities on residential population is also derivable.

14a) $\Omega_{r}^{A P}<\Omega_{r}<\Omega_{r}^{A C}<\Omega_{r}^{C O}<0$

14b) $\quad \Omega_{A}^{A P}>\Omega_{A}>\Omega_{A}^{A C}>\Omega_{A}^{C o}>0$

The relationships between the population effects under the consumption agglomeration assumptions and the congestion assumptions only hold with certainty under the additional assumption mentioned above that $1-G^{\prime} v_{u} u_{A C}^{\prime}=1 /\left(1-F^{\prime} \pi_{u} u_{C o}^{\prime}\right)$. This is an attractive baseline for comparison since it holds the strength of the congestion or consumer 
agglomeration forces to be equal, in a sense, and the differences can thus be attributed to the type of urban scale effect rather than the strength. The comparison between the production agglomeration effect and the other effects holds whatever the strength of the agglomeration.

Looking at the general equilibrium effects of housing supply constraints on the endogenous variables is instructive because this represents the effect of an exogenous decrease in population. These effects consist of the rental effect, and the rental effects' indirect effect on wages and population. For all four urban scale effects, the restriction of housing supply increases rents. The general equilibrium effect on rents can be ordered as follows:

$0<\frac{d r}{d C}^{A P}<\frac{d r}{d C}<\frac{d r}{d C}^{A C}<\frac{d r}{d C}^{C o}$

Inequality (13a) allows us to order the general equilibrium effect on wages across urban scale assumptions. Because $w_{r}^{A P}$ is probably negative and because $w_{r}^{C O} \approx w_{r}^{A C}$ are probably positive, it is probable that:

${\frac{d w^{A P}}{d C}}^{A P} \frac{d w}{d C}<\frac{d w^{A C}}{d C}<\frac{d w^{C o}}{d C}$

with zero falling somewhere between the agglomeration in production $(A P)$ and agglomeration in consumption $(A C)$ effects. Finally, the population effects are all negative. Ordering the magnitude of the effects is difficult because the magnitude of the two components of the general equilibrium effect $\left(\Omega_{r}\right.$ and $\left.\frac{d r}{d C}\right)$ move in opposite directions as one changes the assumptions about the effects of urban scale on productivity and utility. However, all four effects are clearly negative. 
Table I combines these results into tabular form. The top panel reports the signs of the general equilibrium effects under the various urban scale assumptions for the three endogenous variables. The bottom panel reports the theoretically implied correlations. We see that the consistently negative population effects and consistently positive rental effects generate a consistent negative implied covariance between city rents and population. On the other hand, the general equilibrium effects on wages change with the model: they are negative in the agglomeration in production models, positive in the agglomeration for consumers and congestion models, and ambiguous of sign for the neoclassical model. This changes the implied correlations in the second panel. On their own, none of these urban-scale-effects assumptions do a very good job of generating the strong positive relationships between these variables that we observe in the real world.

If urbanization/congestion economies do not generate the pattern of local prices and population that we observe in the data, the question becomes whether natural advantage can explain these patterns, either alone or in combination with the urban scale effects. It can be shown that larger $w_{A}, w_{r}, \Omega_{A}$ and $\Omega_{r}$ all make the general equilibrium effect of natural advantage on rents larger. Because of this fact, and combined with inequalities (13) and (14), it is not possible to know which type of urban scale effect will have the largest rental effect of natural advantage. However, as has been highlighted in the previous sections, this quantity is unambiguously positive.

Holding the rental effect roughly constant, it is almost certain that the general equilibrium effect of natural advantage on wages is positive for the congestion and agglomeration in consumption models. It is likely that the effect is positive in the neoclassical model, while the sign of this effect in the agglomeration in production model 
is ambiguous because the direct effect of natural advantage on wages is combined with a (probably) negative partial effect of rents on wages. Thus, a likely ordering of the general equilibrium wage effects is

$$
\frac{d w^{A P}}{d A}<\frac{d w}{d A}<\frac{d w}{d A}^{A C} \approx \frac{d w}{d A}^{C o}
$$

with the first two terms being of ambiguous sign.

The ordering of the general equilibrium effects of natural advantage on population is also difficult because the partial effects involved $\left(\Omega_{A}\right.$ and $\left.\Omega_{r}\right)$ always have the same sign across models, and because they move in opposite directions when the agglomeration/congestion assumptions are changed. Although this effect is ambiguous in the most general case, it can be signed for more specific functional forms. Appendix 1 shows that this effect will be positive regardless of the type of urban scale effect assumed, at least if residents have CES utility over housing and all other goods. ${ }^{10}$ For the two-good case, this is a fairly general functional form, and can be taken as an example. This proposition is proved under more general assumptions about the utility function in appendix 2.

Table II reports the signs of the theoretical general equilibrium effects of natural advantage and the implied empirical correlations as in table I. ${ }^{11}$ Comparing tables I and II, one thing is clear immediately. Whatever the assumptions one makes about the effects of urban scale on people's or firms' objective functions, the model's output is made much more similar to objective reality with the addition of natural advantage. With natural advantage included in the model, six negative correlations become positive, one becomes

\footnotetext{
${ }^{10} \mathrm{I}$ have also checked the results for a general quasi-linear utility function and reached the same result as long as marginal utility is declining in all other goods.

${ }^{11}$ For this table, I maintain the assumptions laid out in appendix 2.
} 
ambiguous and two ambiguous effects become less ambiguous. ${ }^{12}$ In comparing a model with or without natural advantage, it is clear that a natural advantage model makes the better predictions about how these three city characteristics co-vary.

Comparing across models within table II (assuming natural advantage), a surprising result arises. Agglomeration economies which affect productivity $(A P)$ do the worst in terms of generating the expected patterns. While the effect of natural advantage in combination with agglomeration on rents and population is strong here, the effect on wages is weaker. While we might be willing to assume this effect is positive, it suggests that the correlation between wages and rents might be weak. On the other hand, the congestion effects model $(\mathrm{Co})$ and the model with agglomeration economies in consumption $(A C)$ predict unambiguous positive correlations between all three variables, with the neo-classical model providing a bit of a mix of the two sets of assumptions.

If we imagine a world where potential city-sites have varying levels of both natural advantage $(A)$ and housing supply constraints $(C)$, the results reported in tables I and II reinforce the intuition that the $C o$ and $A C$ models outperform the $A P$ model. Even granting a positive general equilibrium effect of natural advantage on wages in the $A P$ model, the independent variation in $C$, or housing supply, across potential city sites will tend to decrease the correlation between rents and wages in the $A P$ model, while it would tend to increase the correlation between wages and population. For the $C o$ and $A C$ models, this independent variation in $C$ across city sites would tend to increase the correlation between rents and wages while it tended to decrease the correlation between population and rents (and between population and wages). Thus, if the actual landscape

\footnotetext{
${ }^{12}$ The implied correlation between rents and wages in the neoclassical model actually goes from completely ambiguous to probably positive with natural advantage. Although this correlation is somewhat ambiguous, it is definitely more likely to be positive with natural advantage than without.
} 
varies in terms of natural advantage and housing supply constraints, the $A P$ model predicts a stronger correlation between wages and population than between wages and rents, while the $C o$ and $A C$ models predict a stronger relationship between wages and rents than between wages and population. Looking at figures 1 through 3 and the implied correlations (about .82 between wages and rents and about .45 between population and either wages and rents), it is clear that the congestion or agglomeration in consumption models match the data better, at least for America in the early $21^{\text {st }}$ century.

\section{Conclusion.}

This paper has attempted to generate a prevalent feature of economic geography - the positive correlation amongst wages, rents and population - from a simple general equilibrium model with varying assumptions about how urban scale affects firms' profits and residents' utility. While the model is dissimilar to many recent models in the agglomeration literature, it has several virtues. First, the assumptions are quite general. The assumptions needed for the results are that firms like low costs, that residents like high real incomes, that firms and residents vary in their attachment to specific places, and that cities vary with respect to the supply of housing and the natural advantage amenities available to them. This model generates rents, wages and populations for any combination of housing supply constraints and natural advantage. The model is easily modified to make radically different assumptions about the effects of urban scale on firms' and residents' well-being.

Within this framework - and with the additional assumptions that the laws of demand and supply hold, that preferences are well-behaved and that housing is a normal 
good - I am able to derive how natural advantage and housing supply constraints will affect rents, wages and populations, and assess whether the derived patterns conform with observed empirical patterns across a variety of different effects of urban scale. The results show that no assumptions about urban scale generate the pattern of local prices and population without the additional influence of natural advantage. In combination with natural advantage, all four sets of assumptions about urban scale effects do a reasonable job of producing the pattern, although one must give agglomeration in production the benefit of the doubt. Even granting this, however, the combination of variation in natural advantage and in supply constraints suggests different patterns in the relative strength of the relationships, depending on the assumptions one makes about how urban scale affects individual welfare. Production agglomeration economies imply a stronger relationship between wages and population while consumption agglomeration or congestion economies imply a stronger relationship between rents and wages. The predictions of the congestion or consumer agglomeration models, then, are more consistent with the data than the agglomeration model.

The significance of these results is thus twofold. First, the requirement of natural advantage to generate any of the patterns is significant since much of the agglomeration literature has sought to generate cities in a featureless landscape. This is not to say that assuming a featureless landscape implies the belief in such a landscape in reality. The generation of agglomerations on a featureless landscape is important in terms of understanding what goes on in cities and why they form. The featureless plain is the only place to start such a theoretical exploration. These results suggest that while the featureless plain is an important starting place for these explorations, it is not an 
appropriate ending place in our understanding of cities and why they form. If economics is the science of how people make the best of their situation, then it would be surprising if they did not take advantage of the natural variation in the landscape which certainly exists. These results suggest that in the presence of increasing local housing prices (a positively sloped housing supply curve) and heterogeneity in local attachments, agglomeration alone will not induce the positive correlation between housing and labor prices and population. Some natural variation in the landscape is necessary for this pattern to arise.

Assuming some variation in the natural advantage amenity, these results also suggest that at the margins (where we observe real cities), production agglomeration makes for a poorer match with observed data than consumer agglomeration or congestion. This informs the debate on the microfoundations of agglomeration economies. Most of the energy of recent theoretical explorations of agglomeration economies has focused mainly on productivity-related explanations. Duranton and Puga (2004) categorize these microfoundations into sharing, matching and learning effects. ${ }^{13}$ Their discussion of these effects makes it clear that - with the possible exception of risk sharing of job seekers - most of these effects are benefiting producers by making them more profitable or more productive. These results suggest that the microfoundations of urbanization economies in consumption deserve more attention in the future, and that the possibility of substantial marginal congestion economies - which have received very little attention in recent years - also deserves a second look from economists.

\footnotetext{
${ }^{13}$ NEG models combine a mix of production effects (the market access effect) and consumer effects (lower cost of living in the agglomeration). A combination of producer and consumer agglomeration forces in the present model would look more or less like the neo-classical model in its output, but with more negative $\Omega_{r}$.
} 
Of course, to the extent that the models' output is compared to patterns in the prices and populations of already developed cities that are at or near equilibrium, these conclusions may not be consistent with the fundamental forces that cities embody. It is entirely possible that cities form due to production-oriented agglomeration but that these increasing returns may have been exhausted. What these results and the comparison to the data suggest is that at the margin, those production agglomeration economies have been exhausted, and that marginal changes in population and prices are best explained by either congestion economies or by agglomeration economies geared towards consumers. As discussed above, there are many ways to justify such urban scale effects. Indeed, the broad categories of microfoundations discussed in Duranton and Puga (2004) can be interpreted (at least loosely) in terms of affects on consumers' utility instead of firms' profits. Within the NEG model, consumer-oriented agglomeration is already embodied in the form of lower local prices. However, these consumer-oriented agglomeration economies are more latent in these models than explicit. Hopefully, they will receive more formal theoretical and empirical examination in the future.

\section{Appendix 1: Proof that natural advantage increases population for CES utility.}

By definition, the general equilibrium effect of natural advantage will be positive whenever:

A1) $\frac{d \Omega^{X}}{d A}=\Omega_{A}^{X}+\Omega_{r}^{X} \frac{d r^{X}}{d A}>0$.

In equation (A1), the " $X$ " superscript indexes the different models in the paper: agglomeration in production $(A P)$, neoclassical (no superscript), agglomeration in 
consumption $(A C)$ and congestion $(C o)$. Substituting in for the general equilibrium effect of natural advantage on rents and re-arranging terms yields:

$\Omega_{A}^{X}\left(S_{r}-\Omega_{r}^{X} D-\Omega^{X}\left(D_{r}+D_{w} w_{r}^{X}\right)\right)>-\Omega_{r}^{X}\left(\Omega_{A}^{X} D+\Omega^{X} D_{w} w_{A}^{X}\right)$

and thus

$\Omega_{A}^{X}\left(S_{r}-\Omega^{X}\left(D_{r}+D_{w} w_{r}^{X}\right)\right)>-\Omega_{r}^{X} \Omega^{X} D_{w} w_{A}^{X}$

Further manipulation yields:

A2) $\frac{S_{r}}{\Omega^{X} D_{w} w_{A}^{X}}-\frac{D_{r}}{D_{w} w_{A}^{X}}-\frac{w_{r}^{X}}{w_{A}^{X}}>-\frac{\Omega_{r}^{X}}{\Omega_{A}^{X}}$.

Because within every model, $X$, the two terms in the quotient on the r.h.s. of inequality (A2) will share a leading coefficient, and because $v_{A}=0$ for natural advantage type amenities, (A2) can be rewritten as follows:

$\left.\mathrm{A} 2^{\prime}\right) \quad \frac{S_{r}}{\Omega^{X} D_{w} w_{A}^{X}}-\frac{D_{r}}{D_{w} w_{A}^{X}}-\frac{w_{r}^{X}}{w_{A}^{X}}>-\frac{v_{r}}{v_{w} w_{A}^{X}}-\frac{w_{r}^{X}}{w_{A}^{X}}$.

The last terms on each side of the inequality cancel out, and the common $w_{A}^{X}$ term can be multiplied out. Finally, by Roy's identity, the remaining term on the r.h.s. can be replaced by the Marshallian demand for housing: $-v_{r} / v_{w}=D$. After some additional rearrangements we arrive at a more manageable inequality:

A3) $\frac{S_{r}}{\Omega^{X} D_{w}}>D+\frac{D_{r}}{D_{w}}$.

Because the 1.h.s. of inequality (A3) is positive, (A3) and thus (A1) will be satisfied whenever the r.h.s. of inequality (A3) is negative. It is certainly possible for (A3) to hold, since the r.h.s. includes a positive and a negative term. It is easily shown that (A3) holds under Cobb-douglas utility, where $D=\alpha w / r$. 
This result also holds for the more general CES utility function (over housing and all other goods). Under those additional assumptions, demand is:

$D=\left(\frac{\alpha}{r}\right)^{\sigma} w\left(\alpha^{\sigma} r^{1-\sigma}+k\right)^{-1}$

Here, the second price term in the CES demand function has been replaced with a

constant, $k$, since the "other good" is a numeraire and its price will thus not change. The standard substitution of $\sigma=1 /(1-\rho)$ has also been made, so that $\sigma>0$. The partial derivatives needed to assess whether (A3) holds are as follows:

$D_{r}=-\left(\frac{\alpha}{r}\right)^{\sigma} w\left(\alpha^{\sigma} r^{1-\sigma}+k\right)^{-1}\left[\frac{\sigma}{r}+\left(\frac{\alpha}{r}\right)^{\sigma}(1-\sigma)\left(\alpha^{\sigma} r^{1-\sigma}+k\right)^{-1}\right]$

and

$D_{w}=\left(\frac{\alpha}{r}\right)^{\sigma}\left(\alpha^{\sigma} r^{1-\sigma}+k\right)^{-1}$

so that

$\frac{D_{r}}{D_{w}}=-w\left[\frac{\sigma}{r}+(1-\sigma)\left(\frac{\alpha}{r}\right)^{\sigma}\left(\alpha^{\sigma} r^{1-\sigma}+k\right)^{-1}\right]$.

The last two parenthetical terms in the brackets can be substituted either with $D_{w}$ or with $D / w$. The second substitution is more convenient. Substituting the resulting functions into inequality (A3) yields:

$$
\frac{S_{r}}{\Omega^{X} D_{w}}>D-w\left[\frac{\sigma}{r}+(1-\sigma) \frac{D}{w}\right]=\sigma D-\sigma \frac{w}{r} .
$$

As the 1.h.s. is positive, this inequality will hold if the r.h.s. is negative. Because we know that $\sigma>0$, (A4) will hold whenever $r D \leq w$. However, because $w$ is income and 
$r D$ is total expenditure on housing, this inequality must hold to satisfy the budget constraint.

\section{Appendix 2: Proof for more general utility functions.}

Inequality (A3) can be shown to hold for the more general case of all continuous utility functions representing locally non-satiated, strictly convex preferences. These assumptions are quite general. Noting again that the 1.h.s. of inequality (A3) is positive under the assumptions in the paper's model, one must only show that the r.h.s. is negative to prove that natural advantage will increase population. In symbols:

A5) $\quad D+\frac{D_{r}}{D_{w}} \leq 0 \Rightarrow \frac{d \Omega}{d A}^{X}>0$.

Multiplying both sides of inequality (A5) by $D_{w}>0$ yields:

$$
D_{w} D+D_{r} \leq 0
$$

Under the assumptions laid out above, the Slutsky Equation tells us that the 1.h.s. of inequality (A6) is equal to the compensated, or Hicksian own-price effect, which we know to be negative.

Thus, under the very general assumptions of continuous, locally non-satiated, strictly convex preferences, one need only assume that housing is a normal good $\left(D_{w}>0\right)$ to ensure that natural advantage amenities increase population in equilibrium. This is an assumption which has been maintained in the rest of the paper, and which is extremely defensible. 


\section{References:}

Baldwin, Richard E. and Toshihiro Okubo (2006). "Heterogeneous firms, agglomeration and economic geography: Spatial selection and sorting." The Journal of Economic Geography vol. 6(3): 323-346.

Bloomquist, G.C., M.C. Berger and J.P. Hoehn (1988). "New Estimates of Quality of Life in Urban Areas." The American Economic Review vol. 78(1): 89-107.

Clark, Terry Nichols (2003). "Urban Amenities: Lakes, Opera, and Juice Bars, do they drive development?" in Terry Nichols Clark, ed. The City as an Entertainment Machine: Researches in Urban Policy, Vol. 9, (New Amsterdam: Elsevier), 103-140.

Costa, Dora L. and Matthew E. Kahn (2000). "Power Couples: Changes in the locational choice of the college educate, 1940-1990." The Quarterly Journal of Economics, vol. 115(4) : 1287-1315.

Duranton, Gilles and Diego Puga (2004). "Micro-foundations of Urban Agglomeration Economies." chp. 48 in Handbook of Regional and Urban Economics, vol. 4, V. Henderson and J.F. Thisse, eds. Amsterdam: North-Holland: 2063-2117.

Ellison, Glenn and Edward L. Glaeser (1997). (Geographic Concentration in U.S. Manufacturing Industries: A Dartboard Approach." Journal of Political Economy, Vol 105(5), 889-927.

Ellison, Glenn and Edward L. Glaeser (1999). "The Determinants of Geographic Concentration." American Economic Review Papers and Proceedings, vol. 89(2): $311-316$.

Fischer, C.S. (1975). "Towards a subcultural theory of urbanism." The American Journal of Sociology, vol 80(6): 1319-1341.

Florida, Richard (2002)., "Bohemia and economic Geography," Journal of Economic Geography, vol 2(1): 55-71.

Glaeser, Edward L. and Joseph Gyourko (2005). "Urban Decline and Durable Housing." Journal of Political Economy, vol. 113: 345-375.

Glaeser, Edward L., Joseph Gyourko and Ravan Saks (2005). "Why is Manhattan so Expensive?: Regulation and the Rise in House Prices." Journal of Law and Economics, vol. 48(2): 331-370.

Glaeser, Edward, Joseph Gyourko and Ravan Saks (2006). "Urban Growth and Housing Supply." Journal of Economic Geography vol. 6(1): 71-90.

Gyourko, Joseph, Christopher Mayer and Todd Sinai (2006). "Superstar cities." Wharton Real Estate Center Working Paper, June 2006.

Gyourko, Joseph and Albert Saiz (2006). "Construction costs and the supply of housing structure.” Journal of Regional Science, vol 46(4): 661-680. 
Kim, Sukkoo (1999), "Regions, resources and economics geography: Sources of U.S. regional comparative advantage, 1880-1987," Regional Science and Urban Economics, vol. 29, 1-32.

Krugman, Paul (1991). "Increasing Returns and Economic Geography." The Journal of Political Economy, vol. 99(3): 483-499.

Krupka, Douglas (2007). "Location-specific Human Capital, Amenity Valuation and Location Choice.” (August, 2007). IZA Discussion Paper No. 2987. Available at: http://ftp.iza.org/dp2987.pdf

Krupka, Douglas J. and Donaldson, Kwame (2008). "Wages, Rents and Heterogeneous Moving Costs (Second Version)" (February 1, 2008). Andrew Young School of Policy Studies Research Paper No. 08-06 Available at SSRN: http://ssrn.com/abstract=1090249

Ottaviano, Gianmarco I.P., Takatoshi Tabuchi and Jacques-Francois Thisse (2002). "Agglomeration and Trade Revistited." International Economic Review, vol 43(): 409-436.

Ottaviana, Gianmarco I.P. and Jacques-Francois Thisse (2004). "Agglomeration and economic geography," chp. 58 in Handbook of Regional and Urban Economics, vol. 4, V. Henderson and J.F. Thisse, eds. Amsterdam: North-Holland: 2563-2608.

Pflüger, Michael and Jens Südekum (2008). „A synthesis of footloose-entrepreneur new economic geography models: When is agglomeration smooth and easily reversible." Journal of Economic Geography, vol. 8(1), 39-54.

Roback, Jennifer (1982). "Wages, Rents and the Quality of Life." The Journal of Political Economy, vol. 90(6): 1257-78.

Rosenthal, Stuart S. and William C. Strange (2001). "The Determinants of Agglomeration." Journal of Urban Economics, vol. 59(): 191-229.

Tabuchi, Takatoshi (1998). "Agglomeration and dispersion: a synthesis of Alonso and Krugman." Journal of Urban Economics, vol. 44(): 333-351.

Tolley, George S. (1974). "The Welfare Economics of City Bigness." Journal of Urban Economics, vol 1(): 324-345.

Tolley, George S. and John Crihfield (1987). "City size and place as policy issues." chp. 33 in Handbook of Regional and Urban Economics, vol. 2, Edited by E.S. Mills Amsterdam: North-Holland: 1285-1311. 
Figure 1: Average log income and average log rent.

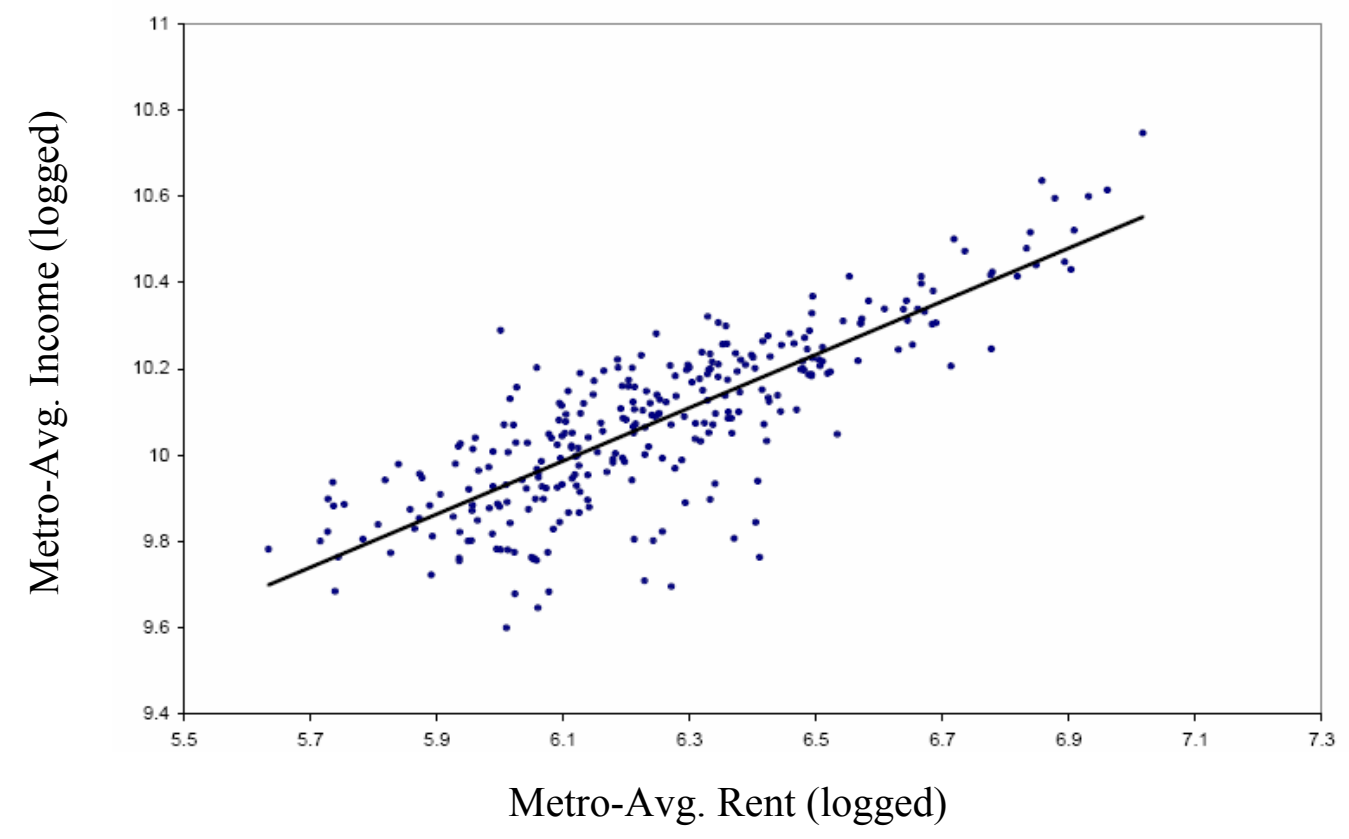

Note: Each data point represents one city. The regression line running through the data has an intercept of 6.227 and slope of .616 (.025 standard error) with an r-squared of .669.

Figure 2: Average log income and logged population.

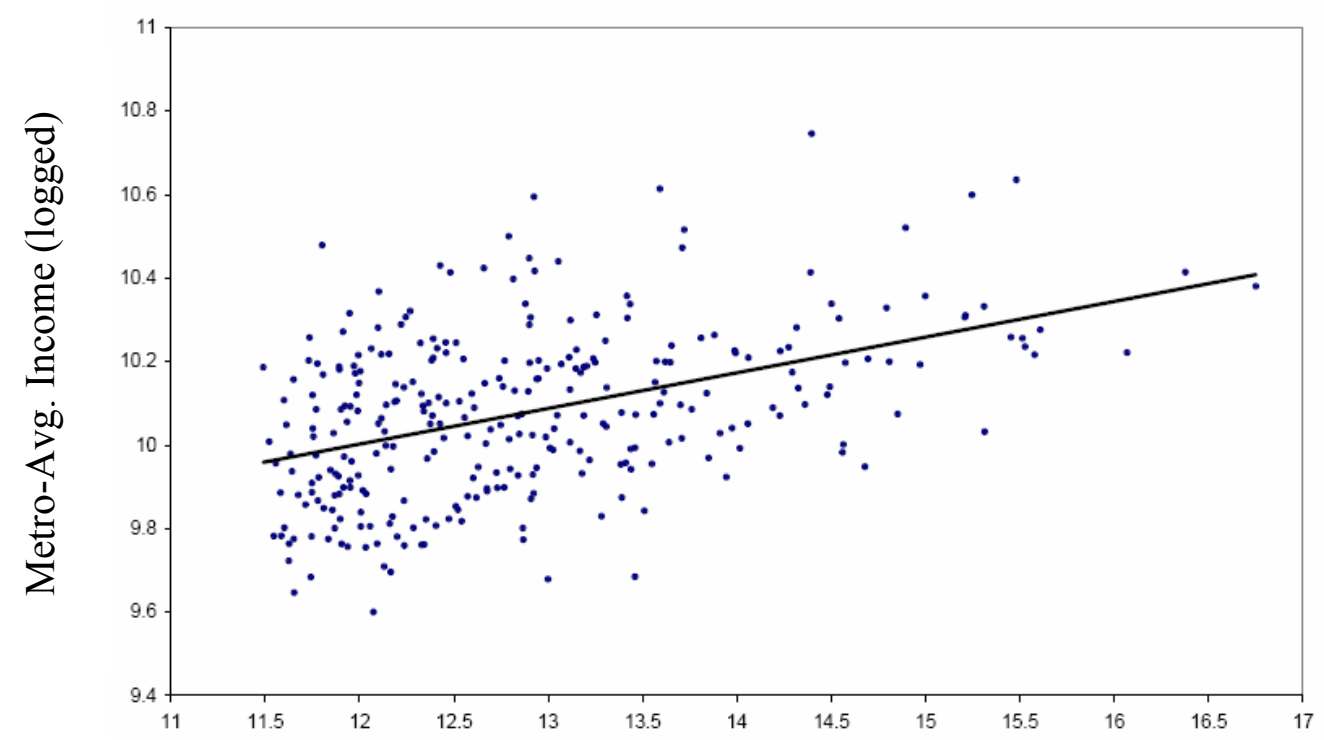

Log Metro Population

Note: Each data point represents one city. The regression line running through the data has an intercept of 8.977 and slope of .085 (.010 standard error) with an r-squared of .197. 
Figure 3: Average log rent and logged population.

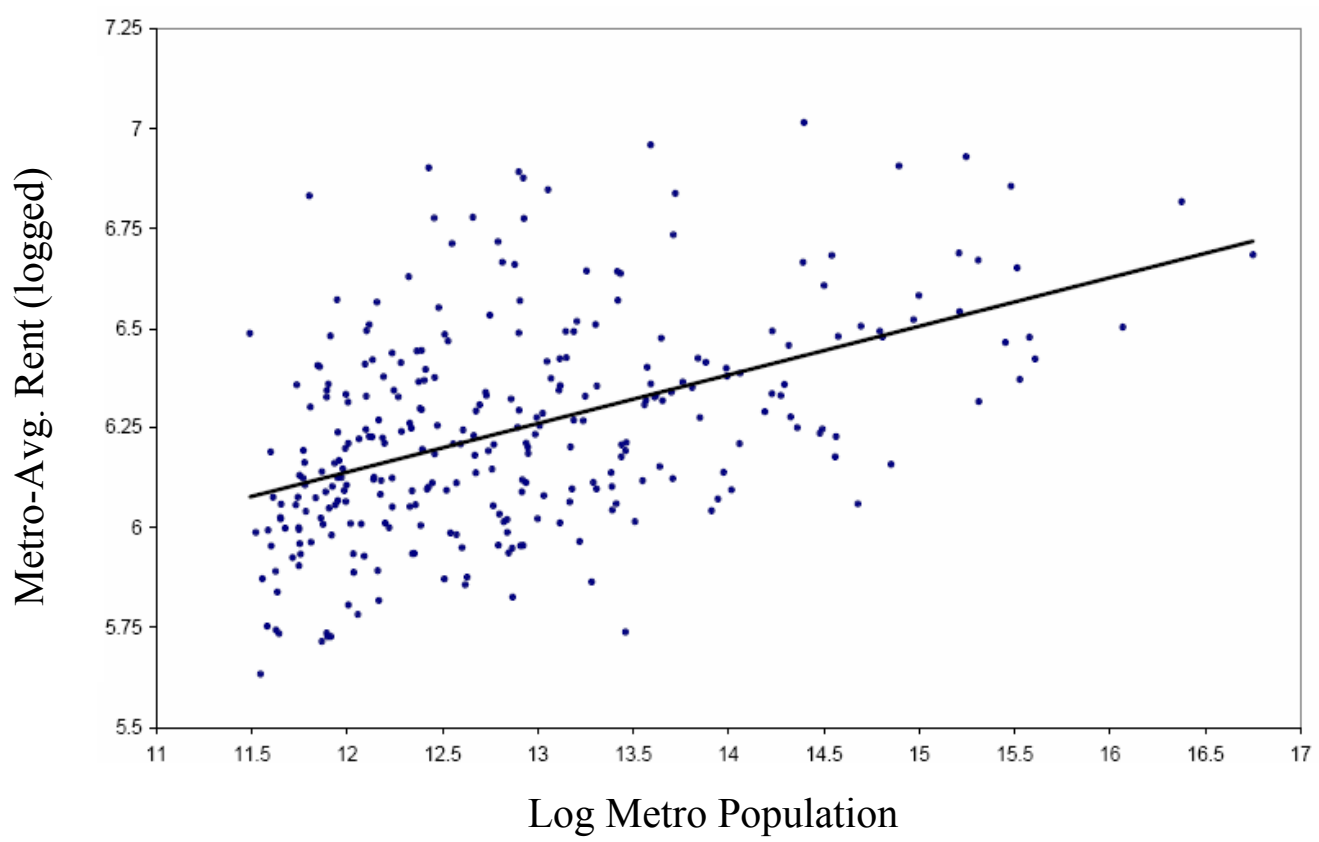

Note: Each data point represents one city. The regression line running through the data has an intercept of 4.677 and slope of .122 (.013 standard error) with an r-squared of .227 .

\section{Figure 4: Rent-Wage Space}

4a: No heterogeneity

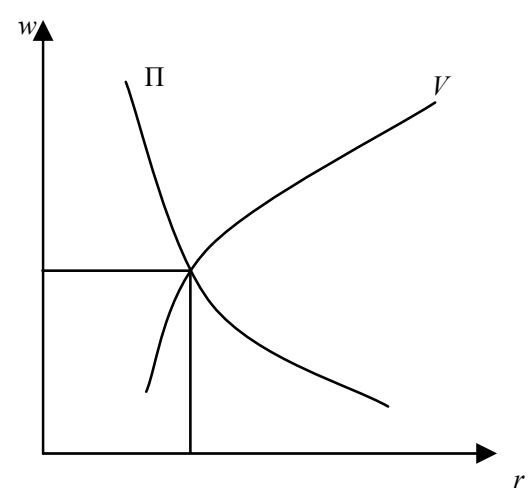

4b: With hetergeneity

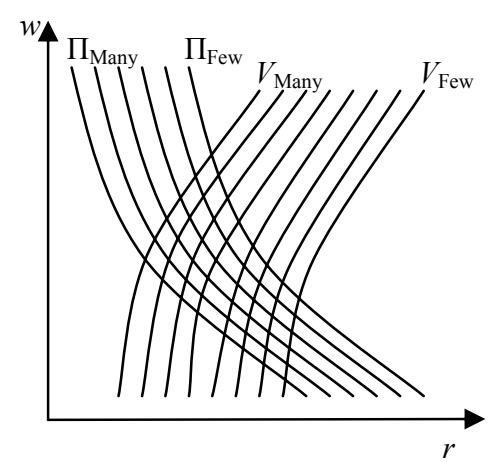


Figure 5: Labor market equilibrium and the wage function

4

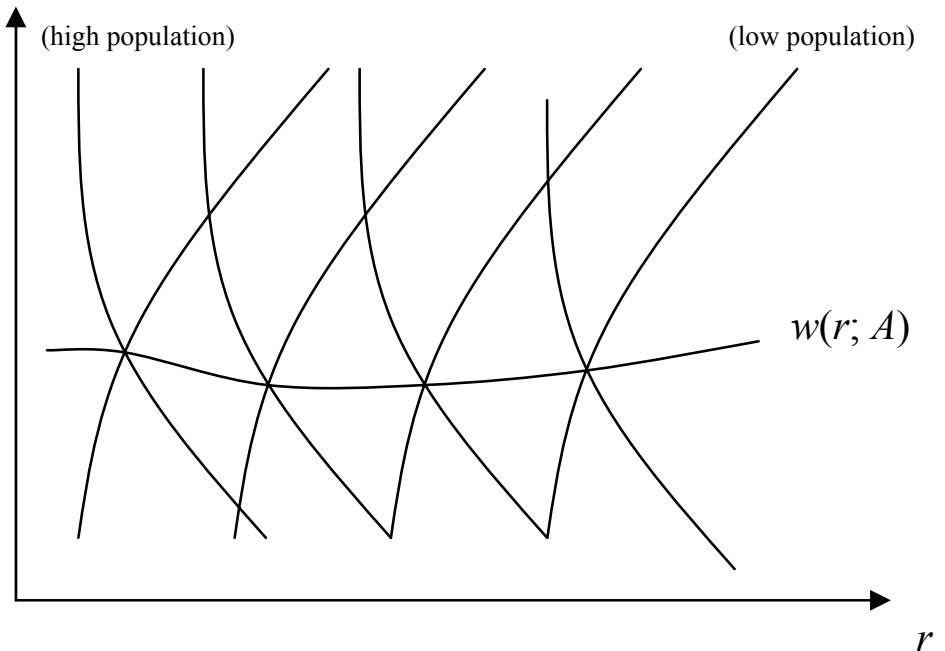

Figure 6: labor market equilibrium and wage curve with agglomeration in production

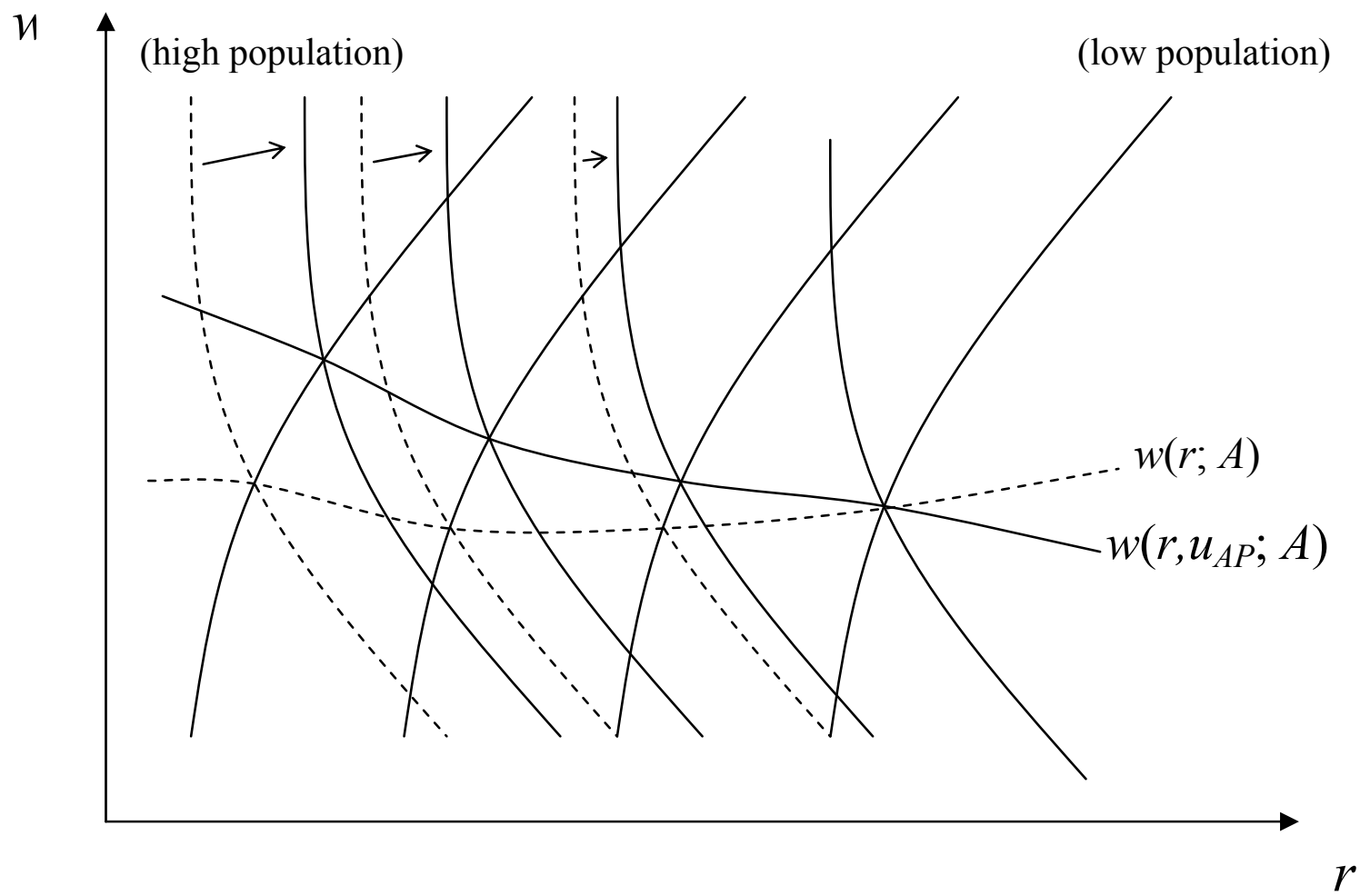


Figure 7: labor market equilibrium and wage curve with congestion in production

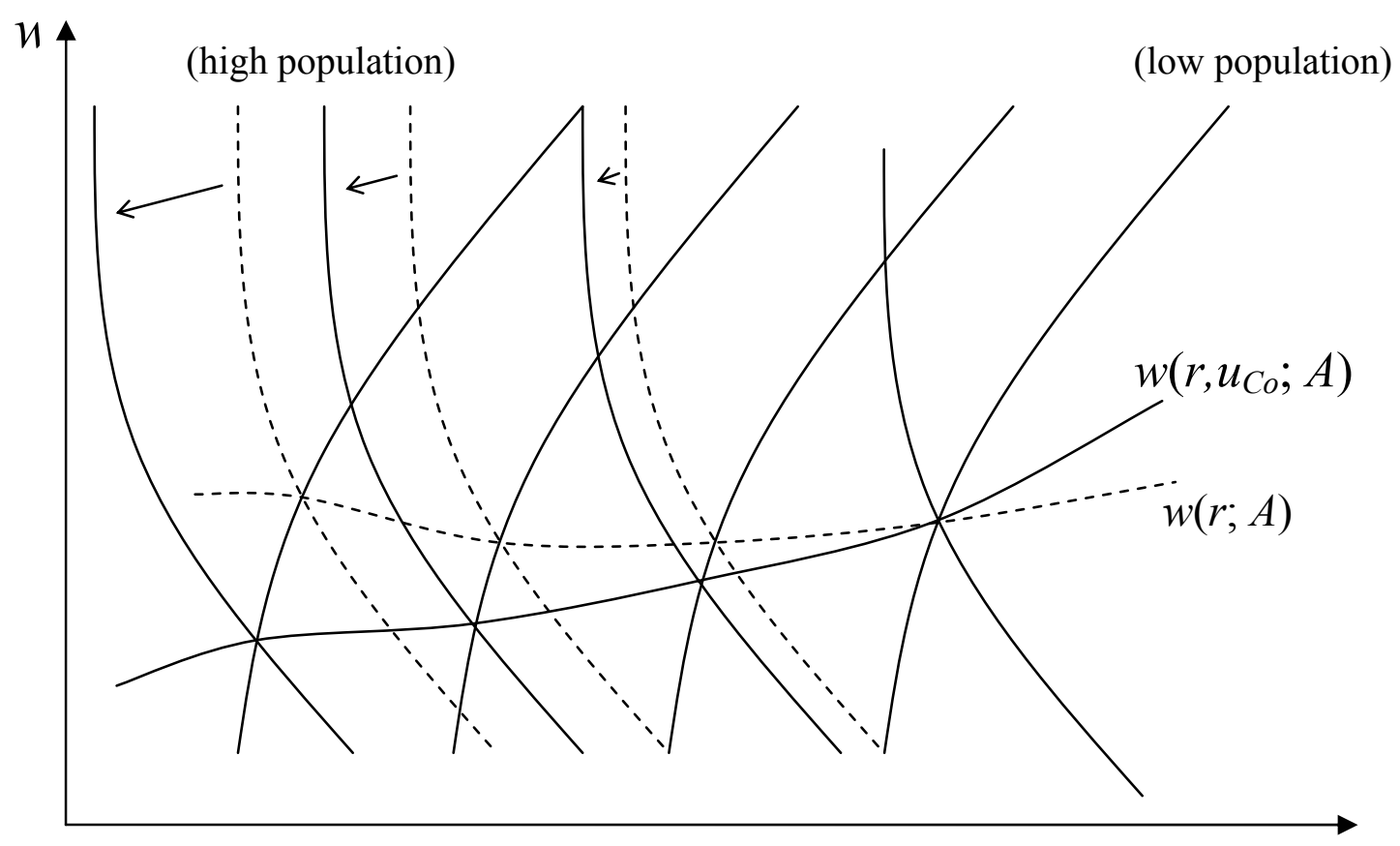

Figure 8: labor market equilibrium and wage curve with agglomeration in consumption

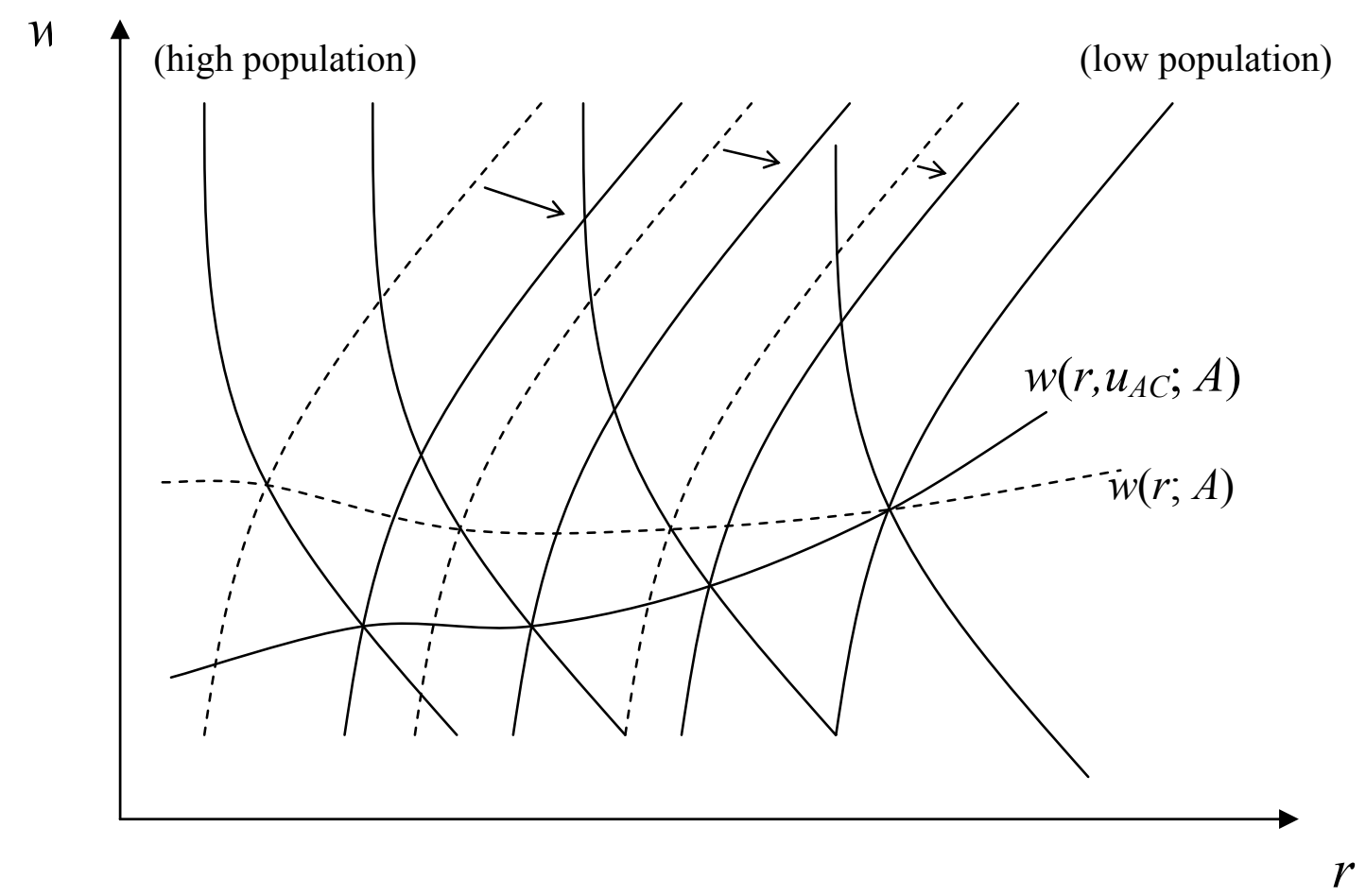


Table I: Effects and implied correlations from supply shifts (C).

\begin{tabular}{|c|c|c|c|c|}
\hline \multirow[b]{2}{*}{ Sign of General Equilibrium Effect: } & \multicolumn{4}{|c|}{ Urban Scale Assumptions: } \\
\hline & $A P$ & Neoclassical & $A C$ & Co \\
\hline Rents & Positive & Positive & Positive & Positive \\
\hline Wages & Negative & Ambiguous & Positive & Positive \\
\hline Population & Negative & Negative & Negative & Negative \\
\hline \multicolumn{5}{|l|}{ Implied Correlations: } \\
\hline Rents/Wages & Negative & Ambiguous & Positive & Positive \\
\hline Wages/Population & Positive & Ambiguous & Negative & Negative \\
\hline Rent/Population & Negative & Negative & Negative & Negative \\
\hline
\end{tabular}

Table II: Effects and implied correlations from Natural Advantage (A).

\begin{tabular}{|c|c|c|c|c|}
\hline \multirow[b]{2}{*}{ Sign of General Equilibrium Effect: } & \multicolumn{4}{|c|}{ Urban Scale Assumptions: } \\
\hline & $A P$ & Neoclassical & $A C$ & Co \\
\hline Rents & Positive & Positive & Positive & Positive \\
\hline Wages & Ambiguous & Amb/Pos & Positive & Positive \\
\hline Population & Positive & Positive & Positive & Positive \\
\hline \multicolumn{5}{|l|}{ Implied Correlations: } \\
\hline Rents/Wages & Ambiguous & Amb/Pos & Positive & Positive \\
\hline Wages/Population & Ambiguous & Amb/Pos & Positive & Positive \\
\hline Rent/Population & Positive & Positive & Positive & Positive \\
\hline
\end{tabular}

